Gut, 1972, 13, 589-595

\title{
Nodular lymphoid hyperplasia with hypogammaglobulinaemia
}

\author{
A. B. AJDUKIEWICZ, G. R. YOUNGS, AND I. A. D. BOUCHIER \\ From the Department of Medicine, Royal Free Hospital, London
}

SUMMARY A patient with nodular lymphoid hyperplasia, who manifested defects in cellular immunity, is presented. The clinical course is discussed and a review included of the 23 patients thus far reported with nodular lymphoid hyperplasia and hypogammaglobulinaemia.

Acquired idiopathic hypogammaglobulinaemia can be associated with a sprue-like syndrome in about $20 \%$ of patients (Gitlin, Gross, and Janeway, 1959). Hermans, Huizenga, Hoffman, Brown, and Markowitz (1966) described the association of hypogammaglobulinaemia with nodular lymphoid hyperplasia of the small intestine, recurrent upper respiratory infections, the malabsorption syndrome with steatorrhoea, and infestation with Giardi lamblia. Nodular lymphoid hyperplasia is relatively rare and is not found in the vast majority of patients with acquired idiopathic hypogammaglobulinaemia. Our purpose is to report a patient with this disorder and to review the literature relating to this subject.

\section{Case History}

The patient, a male aged 62, presented in November 1969 complaining of loss of appetite and vomiting for two weeks and weight loss of $20 \mathrm{~kg}$ over one month. His previous health had been good apart from the symptoms of chronic bronchitis for 30 years. Examination showed evident weight loss and pallor. Haemoglobin was $9.5 \mathrm{~g}$ per $100 \mathrm{ml}$ with macrocytosis of the peripheral blood film. Megaloblasts were present in the sternal marrow biopsy. An augmented histamine test revealed achlorhydria. After a standard Schilling test no radioactive vitamin $B_{12}$ was excreted in the urine and the addition of intrinsic factor improved the 24-hour urinary excretion to only $7 \%$ of the administered dose (normal $>12 \%$ ). Total serum protein was $4.6 \mathrm{~g}$ per $100 \mathrm{ml}$ (albumin $2.9 \mathrm{~g}$, total globulin $1.7 \mathrm{~g}$ ). A barium meal showed an atrophic mucosal pattern and poor peristalsis suggestive of linitis plastica.

After transfusion with 4 pints of blood a laparotomy revealed no abnormality except for a few enlarged mesenteric nodes, one of which was

Received for publication 24 May 1972. removed together with the appendix. A provisional diagnosis of pernicious anaemia was made despite negative tests for parietal cell and intrinsic factor antibodies. The patient was discharged on monthly injections of vitamin $\mathbf{B}_{12}$.

In February 1970 the patient developed diarrhoea, passing up to eight fatty stools per day and he lost a further $10 \mathrm{~kg}$ in weight. In March 1970 pitting oedema of the legs appeared. He was admitted to the Royal Free Hospital. Laboratory investigations showed haemoglobin $10.8 \mathrm{~g}$ per $100 \mathrm{ml}$ (gradually falling after the previous transfusion), serum iron $145 \mu \mathrm{g}$ per $100 \mathrm{ml}$; total iron-binding capacity 165 $\mu \mathrm{g}$ per $100 \mathrm{mg}$; serum albumin $2.0 \mathrm{~g}$ per $100 \mathrm{ml}$; IgG $300 \mathrm{mg}$ per $100 \mathrm{ml}$; IgM $8 \mathrm{mg}$ per $100 \mathrm{ml}$; IgA absent; daily faecal fat excretion $32 \mathrm{~g}$ and $11 \mathrm{~g}$. After intravenous ${ }^{131}$ I-PVP $1.2 \%$ of the dose was recovered in the stool (normal $<1.6 \%$ ). After $25 \mathrm{~g}$ of d-xylose orally the serum level at two $\mathrm{hr}$ was $12.4 \mathrm{mg}$ per $100 \mathrm{ml}$ (normal $>30 \mathrm{mg}$ per $100 \mathrm{ml}$ ) and the urine levels were correspondingly low. Urinary indican excretion was $12 \mathrm{mg}$ and $40 \mathrm{mg}$ per 24 hours (normal 28-68 $\mathrm{mg}$ per $24 \mathrm{hr}$ ). Bilirubin, alkaline phosphatase, aspartate transaminase, and prothrombin time were normal. Duodenal tryptic activity, measured after the administration of a Lundh test meal, was in the low normal range. A barium meal and followthrough examination revealed multiple nodules, 2-5 $\mathrm{mm}$ diameter, throughout the small intestine (Figs. 1 and 2). Jejunal biopsy $10 \mathrm{~cm}$ from the duodenaljejunal flexure showed normal villi but the submucosa was infiltrated with large numbers of lymphocytes. Plasma cells were scanty or absent. The patient received a course of ampicillin and then tetracycline with no improvement.

In July 1970 the patient deteriorated and the diarrhoea persisted. On examination he was pyrexial $\left(\mathrm{T} 38.9^{\circ} \mathrm{C}\right.$ ) and there was gross ascites, oedema of the legs and trunk, and signs of a left basal pneumonia. A chest radiograph showed an area of left basal 


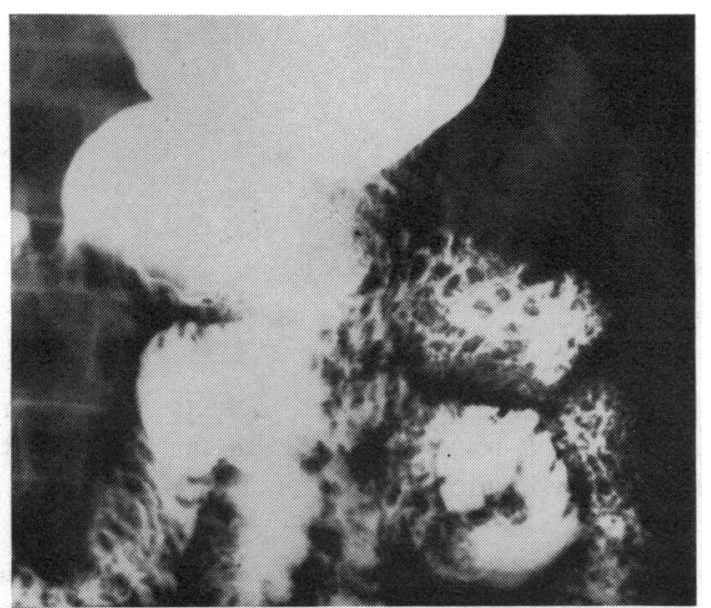

Fig. 1

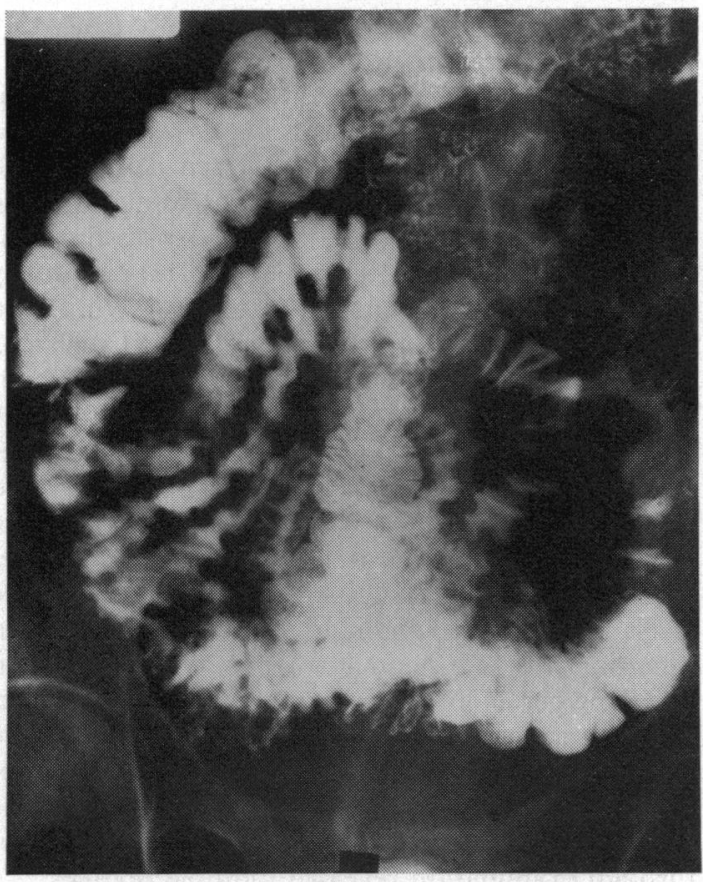

Fig. 2

Figs. 1 and 2 Barium follow-through examination showing multiple small filling defects in the upper small intestine (Fig. 1) and ileum (Fig. 2).

consolidation containing an air-filled cavity. Laboratory investigations showed: haemoglobin $9.8 \mathrm{~g}$ per $100 \mathrm{ml}$; serum iron $45 \mu \mathrm{g}$ per $100 \mathrm{ml}$; total ironbinding capacity $330 \mu \mathrm{g}$ per $100 \mathrm{ml}$; serum and red cell folate normal; faecal fat excretion $4 \mathrm{~g}$ per 24 hours; urinary indicans $0,0,5$, and $5 \mathrm{mg}$ per 24 hours; serum albumin $2.0 \mathrm{~g}$ per $100 \mathrm{ml}$; IgG $55 \mathrm{mg}$ per $100 \mathrm{ml}$; IgM and IgA absent. The ascitic fluid protein was $100 \mathrm{mg}$ per $100 \mathrm{ml}$. Despite the low urinary indicans duodenal intubation yielded a growth of indole-fermenting $E$. coli $\left(10^{7}\right.$ organisms per $\mathrm{ml})$, Strep. viridans $\left(10^{6}\right.$ organisms per $\left.\mathrm{ml}\right)$, and non-haemolytic streptococci $\left(10^{6}\right.$ organisms per $\left.\mathrm{ml}\right)$. No deconjugated bile acids were found in the duodenal juice. Serum bile acids were $2 \mu \mathrm{mol}$ per litre (normal $<5 \mu \mathrm{mol}$ per litre).

The patient was treated with intramuscular gammaglobulin injections $(750 \mathrm{mg}$ daily for one week, then alternate days), ampicillin, trimethoprim, sulphamethoxazole, oral medium-chain triglycerides, and a total dose infusion of iron dextran. The antibiotics were continued for two weeks and the gammaglobulin injections for five weeks. A thiazide diuretic was given with liberal oral potassium supplements because of hypokalaemia.

The pneumonia and pulmonary abscess resolved and the patient slowly improved. Further antibiotics and gammaglobulin were not needed. Treatment continued with oral iron, intramuscular vitamin $\mathbf{B}_{\mathbf{1 2}}$, thiazide diuretic, potassium supplements, and medium-chain triglycerides. The diarrhoea persisted although faecal fat estimations were normal. The ascites and oedema had disappeared by October 1970. Investigations in December 1970 showed: haemoglobin $11.0 \mathrm{~g}$ per $100 \mathrm{ml}$; faecal fat $2 \mathrm{~g}$ per 24 hours; serum albumin $2.9 \mathrm{~g}$ per $100 \mathrm{ml}$; IgG 210 mg per $100 \mathrm{ml}$; IgM $11 \mathrm{mg}$ per $100 \mathrm{ml}$; IgA absent. The diuretic and the medium-chain triglycerides were stopped.

The patient continued to improve and by January $1972 \mathrm{had}$ regained $23 \mathrm{~kg}$ in weight. There was no oedema and no evidence of active chest infection. Laboratory investigations showed: haemoglobin $15.8 \mathrm{~g}$ per $100 \mathrm{ml}$; albumin $4.0 \mathrm{~g}$ per $100 \mathrm{ml}$; IgG $450 \mathrm{mg}$ per $100 \mathrm{ml} ;$ IgM $0 \mathrm{mg}$ per $100 \mathrm{ml} ; \mathrm{IgA} 0 \mathrm{mg}$ per $100 \mathrm{ml}$. The Schilling test performed with and without intrinsic factor showed no significant change. Duodenal juice contained large numbers of Giardia lamblia trophozoites and on culture grew $5 \times 10^{7}$ anaerogenic $E$. coli. Thin-layer chromatography of duodenal juice showed the presence of a relatively large proportion of deconjugated bile acids. Urinary indican excretion was $28 \mathrm{mg}$ per 24 hours. Faecal fat was $14.6 \mathrm{~g}$ per 24 hours. Peroral duodenoscopy (Fig. 3) showed multiple pale raised nodules thickly scattered in the duodenal mucosa with occasional areas free from nodules. Jejunal biopsy (Fig. 4) showed a lymphoid nodule.

\section{FAMILY HISTORY}

The father and a paternal uncle died of carcinoma of the colon. Two brothers, aged 65 and $68 \mathrm{yr}$, are 

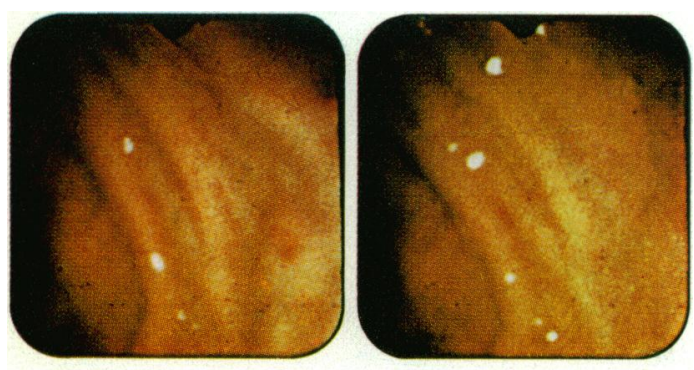

A
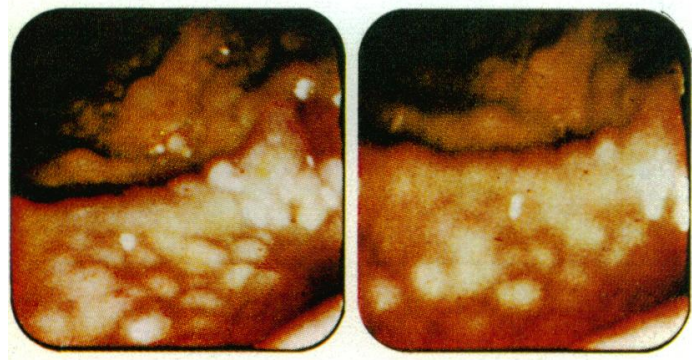

B

Fig. 3 Photograph through fibre duodenoscope showing (A) normal duodenal mucosa and (B) multiple discrete nodules in the duodenum of the patient. alive, although the former had a squamous cell carcinoma of the bronchus resected 24 years ago. They have no smooth muscle, mitochondrial, parietal cell, or intrinsic factor antibodies. Their serum immunoglobulins are normal.

\section{HISTOLOG Y}

On gastric biopsy, the mucosa was atrophic.

Jejunal biopsy showed on dissecting microscopy that most villi were leaf shaped. Histologically villi appeared normal or only slightly broadened and shortened. The lamina propria contained several lymphoid follicles, some of them with germinal centres. Where follicles extended to the surface epithelium, the latter was stretched.

The appendix showed mild scarring only.

The rectum showed acute inflammatory infiltration, mild atrophy, and reduction in goblet cells.

A mesenteric lymph node showed mild follicular hyperplasia.

All tissues examined contained very few plasma cells.

\section{IMMUNOLOGY}

Serum $\operatorname{IgM}$ and $\operatorname{IgA}$ were present only in trace amounts $(0-12 \mathrm{mg} / 100 \mathrm{ml})$ and $\mathrm{IgG}$ varied between 55 and $350 \mathrm{mg} / 100 \mathrm{ml}$. Saliva and duodenal juice did not contain IgA. No antibodies were produced after

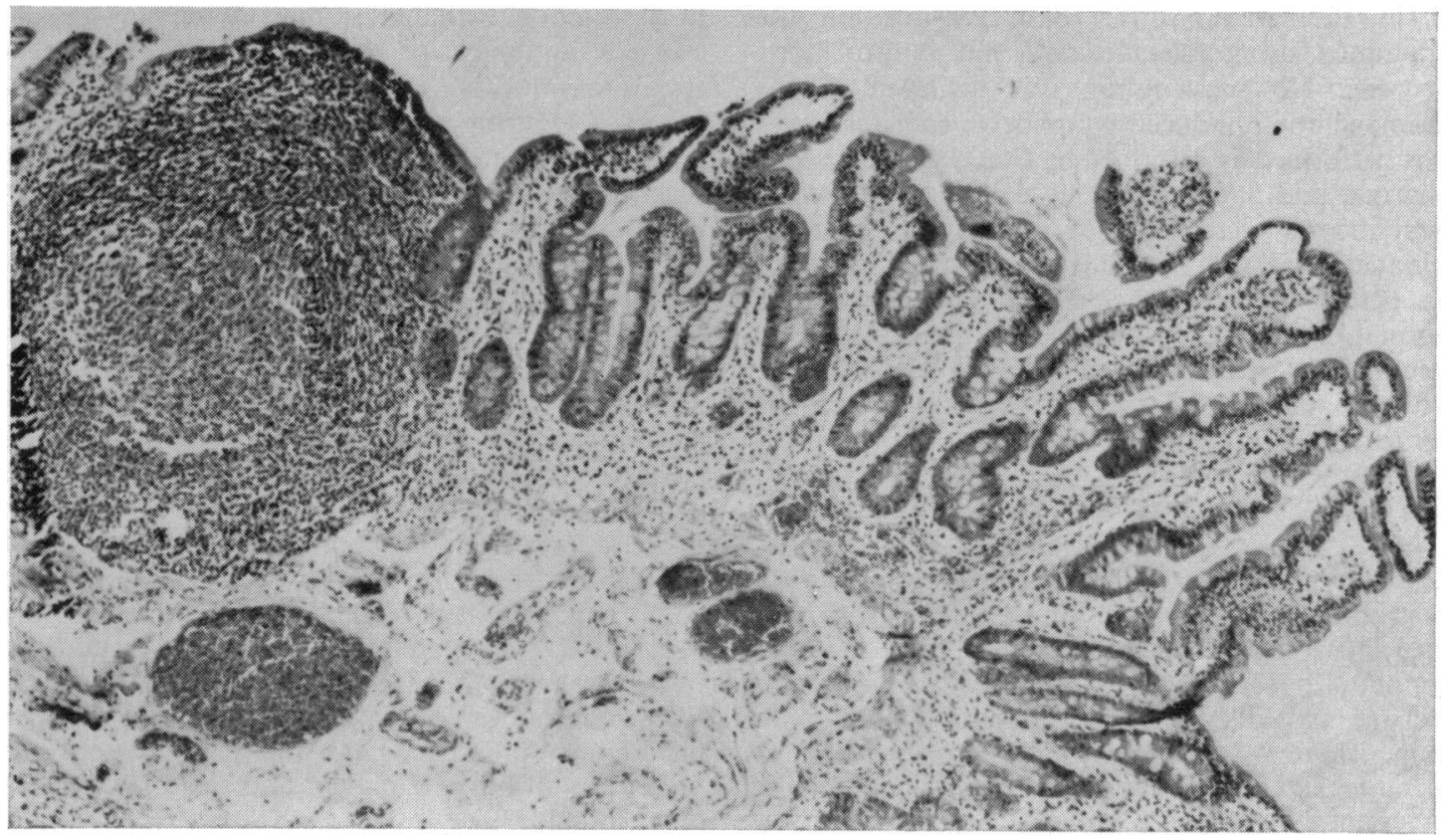

Fig. 4 Jejunal biopsy showing lymphoid follicle and relatively normal villi. 


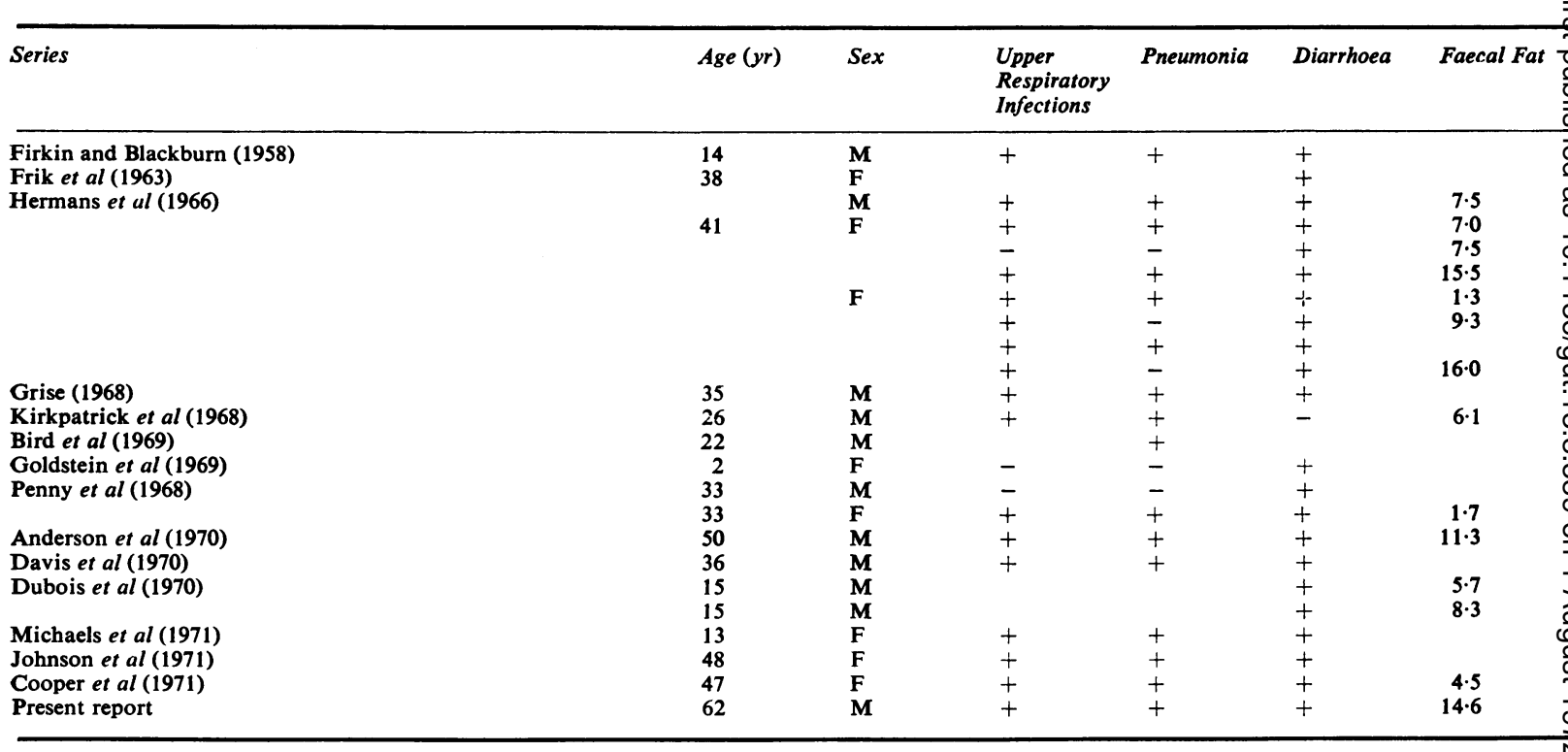

Table Nodular lymphoid hyperplasia and hypogammaglobulinaemia

$+=$ present; $-=$ absent; $N=$ normal.

subcutaneous haemocyanin indicating impaired humoral immunity. Reticulin antibodies were absent. Cellular immunity was tested using skin tests and lymphocyte transformation. The Mantoux test (1 in 100) was positive. Skin sensitization was attempted using haemocyanin and dinitrochlorobenzene. No sensitization was achieved. Phytohaemagglutinin-induced lymphocyte transformation was performed as described by Fox, James, Scheuer, Sharma, and Sherlock (1969) except that 2 million lymphocytes were used in each culture, $0.5 \mu \mathrm{c}$ tritiated thymidine was added to each culture for 18 $\mathrm{hr}$ before stopping the reaction. Results in 20 normal patients gave 70000-140000 counts per minute. Our patient's lymphocytes gave $41000 \mathrm{cpm}$, while a normal control's lymphocytes cultured concurrently produced $99000 \mathrm{cpm}$.

\section{Discussion}

Lymphoid hyperplasia may occur anywhere in the gastrointestinal tract from the base of the tongue to the anus. Feiber and Schaefer (1966) described lymphoid hyperplasia of the terminal ileum in four teenage patients who presented with abdominal pain. There was no history of diarrhoea and no mention is made of serum immunoglobulins. Lymphoid hyperplasia of the colon has been described in children (Capitanio and Kirkpatrick, 1970). It is a benign disorder and may represent the normal hyperplasia of lymphoid tissue that occurs in childhood.

Hermans et al (1966) described eight patients with nodular lymphoid hyperplasia of the small intestine in association with hypogammaglobulinaemia, decreased antibody production, recurrent upper respiratory infections (often pneumonia), the malabsorption syndrome with steatorrhoea and a maintained ability to develop delayed hypersensitivity reactions. Associated manifestations included splenomegaly in four patients, eczematoid dermatitis (3), pernicious anaemia (1), achlorhydria (2), carcinoma of the stomach (1) and the colon (1), lymphoid hyperplasia of the colon (2), and Giardia lamblia infestation of the intestine (6). There have been other reports of this disorder but there has been no summary of the clinical details. In view of this we have compiled a table of the reported cases and have included our patient.

There have been 23 reports of the association of nodular lymphoid hyperplasia of the small intestine with hypogammaglobulinaemia. Fifteen of the subjects were male and nine were female, and apart from the 2-yr-old girl all were aged 15-62 years. Recurrent upper respiratory infections as well as pneumonia were frequent complaints. Diarrhoea was present in all but one patient and steatorrhoea was often found.

Giardia lamblia was found in 14 out of 20 patients. In our patient, as in some other reports, Giardia 


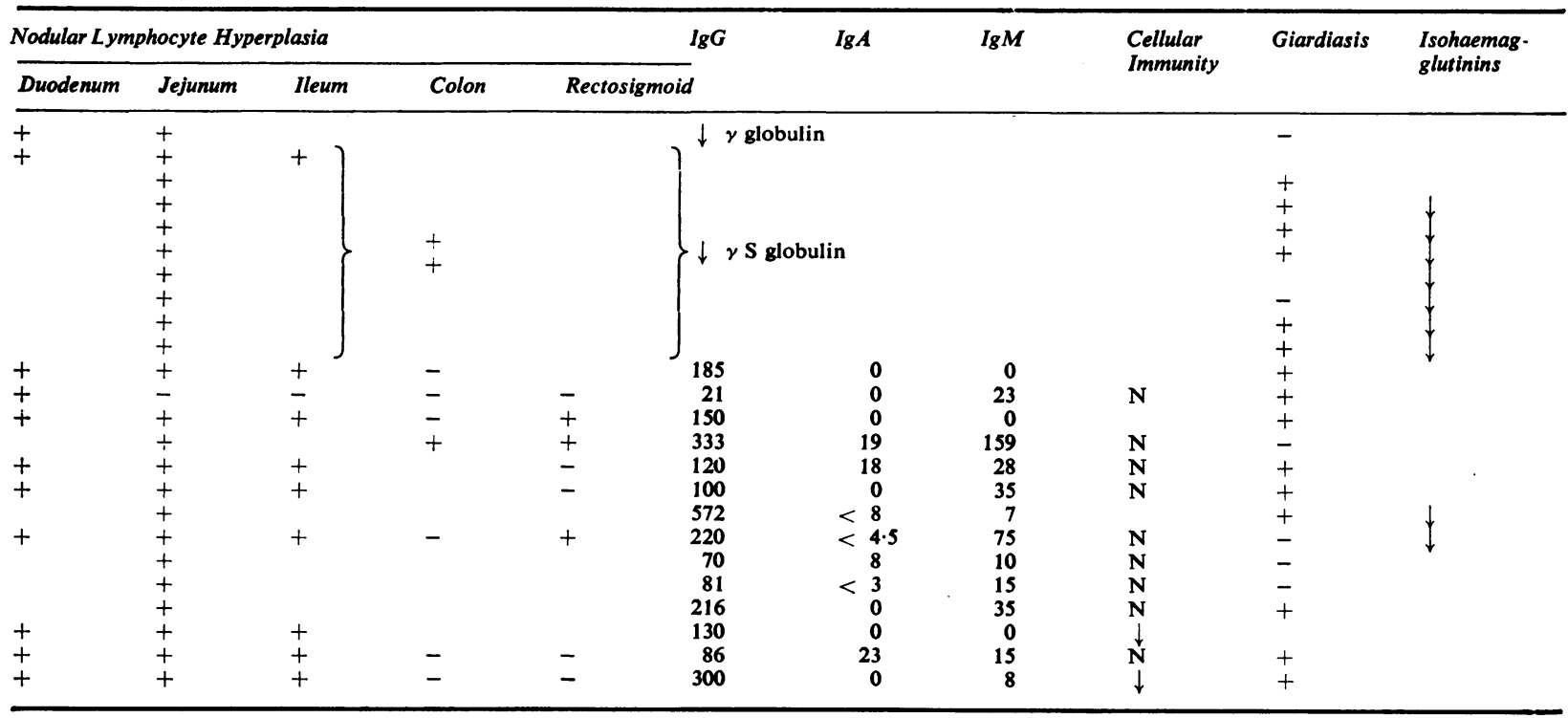

Table Nodular lymphoid hyperplasia and hypogammaglobulinaemia

$+=$ present; - = absent; $\mathbf{N}=$ normal.

lamblia trophozoites were found in the duodenal aspirate although the cysts were not seen in the stool. The relationship of the parasite to the diarrhoea and steatorrhoea is not clear in this condition as its eradication with quinacrine can produce improvement or can be without effect. It is, however, well known that malabsorption may occur in giardiasis (Hoskins, Winawer, Broitman, Gottleib, and Zamcheck, 1967).

Nodular lymphoid hyperplasia was seen in the proximal small intestine of all patients either on intestinal biopsy or barium follow-through examination. It was present in the large intestine in five of the patients. A 13-yr-old boy with nodular lymphoid hyperplasia of the small intestine was reported by Gryboski, Self, Clemett, and Herskovic (1968). Serum IgG and IgM were normal but the IgA was low. Giardia lamblia cysts were found in the stool. Tetracycline and the monthly administration of plasma controlled the diarrhoea. Milano, Lawrence, and Horowitz (1971) reported a 21-yr-old man with nodular lymphoid hyperplasia of the ileum, colon, and rectum. Giardia lamblia were present in the stool but the serum immunoglobulins were normal. This suggests that nodular lymphoid hyperplasia may occur in a whole spectrum of disorders with or without abnormalities of serum immunoglobulins.

Hypogammaglobulinaemia is a rare cause of steatorrhoea (McCarthy, Austad, and Read, 1965). These workers reported a 28-yr-old woman who had a normal jejunal mucosa and who responded to gammaglobulin injections. However, patients with hypogammaglobulinaemia and malabsorption may have an atrophic jejunal mucosa (Collins and Ellis, 1965). The response to treatment varies depending on whether antibiotics, a gluten-free diet, or $\gamma$ globulin injections are used. Hypogammaglobulinaemia may be associated with a thymoma and may be a complication of lymphoma.

Coeliac disease can be associated with a deficiency of IgM (Hobbs and Hepner, 1968) or elevated levels of IgA (Immonen, Kouvalainen, and Visakorpi, 1966). Crabbé and Heremans (1967) reported a patient with coeliac disease who had absent serum IgA and responded to a gluten-free diet, but the serum IgA remained undetectable. Hermans et al (1966) mention two patients who had malabsorption, IgA deficiency, and responded to a gluten-free diet. They state that in one of them 'the mucosal alterations of the small intestine were those of nodular lymphoid hyperplasia'. Absence or deficiency of IgA is the commonest immunoglobulin abnormality to be found in patients with nodular lymphoid hyperplasia with hypogammaglobulinaemia. Bull and Tomasi (1968) have discussed the intestinal disorders seen in patients with IgA deficiency and have emphasized that a lack of IgA may occur in apparently healthy individuals with no gastrointestinal abnormality.

The mechanism of the diarrhoea or malabsorption commonly seen in patients with nodular lymphoid 
hyperplasia and hypogammaglobulinaemia is not clear. Our patient, like others reported, had no evidence of liver disease and had normal pancreatic function. The jejunal mucosa revealed nodular lymphoid hypoplasia and only slight abnormality of the villi. The report by Hermans and Markowitz (1966) includes one patient with 'mucosal atrophy' and Johnson, Goldberg, Pops, and Weiner (1971) noted some blunting of the villi in their patient. Sahba and Dobbins (1970) report a 42-yr-old male with hypogammaglobulinaemia whose intestinal biopsies, obtained over a six-year period, showed progression from normal mucosal villous structure to a severe mucosal lesion.

Bacterial contamination of the small intestine is often mentioned as an aetiological factor for the diarrhoea or the malabsorption. Direct evidence for this is lacking, but some indirect evidence is suggestive. Some patients previously reported have responded to oral antibiotics. Our patient had $E$. coli $\left(10^{7} / \mathrm{ml}\right)$ in the jejunum and the presence of deconjugated bile acids in the jejunal juice. Further evidence is provided by Gleich and Hoffman (1971). They reported a man with acquired hypogammaglobulinaemia, whose diarrhoea responded to cholestyramine. Periods with diarrhoea were marked by the presence of uncommon secondary bile acids, derived from bacterial conversion of primary bile acids, in bile and in faeces.

Cellular immunity has been assessed in 12 patients and has been reported as normal in all but two. A 48-yr-old woman (Cooper, Lawton, and Brockman, 1971) was shown to have a quantitative deficit in cellular immunity. Our patient's lymphocytes also showed a depressed ability to transform in the presence of phytohaemagglutinin. It is not clear whether this was due to a lymphocyte-depressing factor in the serum. Although the Mantoux test was positive, he was unable to develop delayed hypersensitivity to haemocyanin or dinitrochlorobenzene. These tests suggest that cellular immunity was impaired.

Our patient has put on weight, has no diarrhoea, and is well at present, and yet has bacterial contamination of the proximal small intestine, deconjugated bile acids in the jejunal juice, and steatorrhoea. It is not clear why the clinical status of these patients varies with time and why it may be unrelated to their treatment. Perhaps this disorder is not a static one. Nodular lymphoid hyperplasia may represent a compensatory mechanism by the gut immune system to the repeated antigenic stimuli presented to the alimentary tract in the form of bacteria and not handled by the usual antibody response. It may be possible to distinguish patients by virtue of their cellular immunity or their secretory immunoglobulins. It is suggested that nodular lymphoid hyperplasia and hypogammaglobulinaemia may each occur as part of a spectrum of disorders.

We are grateful to Dr C. Symonds for referring the patient, Dr P. Scheuer for reviewing the histology, Mr G. Murphy for the bile salt studies, and Dr V. Guistino for the lymphocyte transformations. A.B.A. is supported by the Davis Fund.

\section{References}

Anderson, F. L., Pellegrino, E. D., and Schaefer, J. W. (1970). Dysgammaglobulinemia associated with malabsorption and tetany. Amer. J. dig. Dis., 15, 279-286.

Bird, D. C., Jacobs, J. B., Silbiger, M., and Wolff, S. M. (1969). Hypogammaglobulinaemia with nodular lymphoid hyperplasia of the intestine. Radiology, 92, 1535-1536.

Bull, D. M., and Tomasi, T. B. (1968). Deficiency of immunoglobulin $A$ in intestinal disease. Gastroenterology, 54, 313-320.

Capitanio, M. A., and Kirkpatrick, J. A. (1970). Lymphoid hyperplasia of the colon in children. Radiology, 94, 323-327.

Collins, J. R., and Ellis, D. S. (1965). Agammaglobulinaemia, malabsorption and rheumatoid-like arthritis. Amer. J. Med., 39, 476-482.

Cooper, M. D., Lawton, A. R., and Bockman, D. E. (1971). Agammaglobulinaemia with B lymphocytes. Lancet, 2, 791-795.

Crabbé, P. A., and Heremans, J. F. (1967). Selective IgA deficiency with steatorrhea. Amer. J. Med., 42, 319-326.

Davis, S. D., Eidelman, S., and Loop, J. W. (1970). Nodular lymphoid hyperplasia of the small intestine and sarcoidosis. Arch. intern. Med., 126, 668-672.

Dubois, R. S., Roy, C. C., Fulginiti, V. A., Merrill, D. A., and Murray, R. L. (1970). Disaccharidase deficiency in children with immunologic deficits. J. Pediat., 76, 377-385.

Fieber, S. S., and Schaefer, H. J. (1966). Lymphoid hyperplasia of the terminal ileum-a clinical entity? Gastroenterology, 50, 83-98.

Firkin, B. G., and Blackburn, C. R. B. (1958). Congenital and acquired agammaglobulinaemia. Quart. J. Med., 27, 187-205.

Fox, R. A., James, D. G., Scheuer, P. J., Sharma, O., and Sherlock, S. (1969). Impaired delayed hypersensitivity in primary biliary cirrhosis. Lancet, 1, 959-962.

Frik, W., Heinkel, K., and Zeitler, G. (1963). Vermehrung und Hyperplasiev on Lymphfollikeln als Ursache granulärer Füllungsdefekte im Röntgenbild des gesamten Dünndarms. Fortschr. Röntgenstr., 99, 65-71.

Gitlin, D., Gross, P. A. M., and Janeway, C. A. (1959). The gamma globulins and their clinical significance. II Hypogammaglobulinaemia. New Engl. J. Med., 260, 72-76.

Gleich, G. J., and Hofmann, A. F. (1971). Use of cholestyramine to control diarrhea associated with acquired hypogammaglobulinemia. Amer. J. Med., 51, 281-286.

Goldstein, G. W., Krivit, W. J., and Hong, R. (1969). Hypoimmunoglobulin $\mathbf{G}$, hyperimmunoglobulin $\mathbf{M}$, intestinal nodular hyperplasia and thrombocytopenia: an unusual association. Arch. Dis. Child., 44, 621-624.

Grise, J. W. (1968). Dysgammaglobulinemia with nodular lymphoid hyperplasia of the small intestine. Radiology, 90, 579-580.

Gryboski, J. D., Self, T. W., Clemett, A., and Herskovic, T. (1968) Selective immunoglobulin $\mathbf{A}$ deficiency and intestinal nodular lymphoid hyperplasia: correction of diarrhea with antibiotics and plasma. Pediatrics, 42, 833-836.

Hermans, P. E., Huizenga, K. A., Hoffman, H. N., Brown, A. L., Jr. and Markowitz, H. (1966). Dysgammaglobulinemia associated with nodular lymphoid hyperplasia of the small intestine. Amer. J. Med., 40, 78-89.

Hobbs, J. R., and Hepner, G. W. (1968). Deficiency of $\gamma \mathrm{M}$-globulin in coeliac disease. Lancet, 1, 217-220.

Hoskins, L. C., Winawer, S. J., Broitman, S. A., Gottlieb, L. S., and Zamcheck, N. (1967). Clinical Giardiasis and intestinal malabsorption. Gastroenterology, 53, 265-279.

Immonen, P., Kouvalainen, K., and Visakorpi, J. K. (1966). The immunoelectrophoretic gamma-A globulin in malabsorption. Ann. Paediat., 207, 269-276.

Johnson, B. L., Jr., Goldberg, L. S., Pops, M. A., and Weiner, M. 
(1971). Clinical and immunological studies in a case of nodular lymphoid hyperplasia of the small bowel. Gastroenterology, 61, 369-374.

Kirkpatrick, C. H., Waxman, D., Smith, O. D., and Schimke, R. N. (1968). Hypogammaglobulinemia with nodular lymphoid hyperplasia of the small bowel. Arch. intern. Med., 121, 273277.

McCarthy, C. F., Austad, W. I., and Read, A. E. A. (1965). Hypogammaglobulinemia and steatorrhea. Amer. J. dig. Dis., 11, 945-957.

Michaels, D. L., Go, S., Humbert, J. R., Dubois, R. S., Stewart, J. M., and Ellis, E. F. (1971). Intestinal nodular lymphoid hyperplasia, hypogammaglobulinaemia and hematologic abnor- malities in a child with a ring 18 chromosome. J. Pediat., 79, 80-88.

Milano, A. M., Lawrence, L. R., and Horowitz, L. (1971). Nodular lymphoid hyperplasia of the small intestine and colon with Giardiasis. Amer. J. dis. Dis., 16, 735-737.

Penny, R., Glasson, R., Goulston, K., McCredie, K., Thorpe, M. and Wells, J. (1968). Nodular lymphoid hyperplasia of the small intestine associated with hypogammaglobulinaemia. In Proceedings of the Third Asian-Pacific Congress of Gastroenterology, pp. 46-53.

Sahba, M. M., and Dobbins, W. O., III. (1970). A possible explanation for the intestinal lesion in Agammaglobulinemia. (Abstr.). Gastroenterology, 58, 991. 